Article

\title{
Intangible Cultural Heritage and Sustainable Tourism in Córdoba, Spain
}

\author{
Francisco González Santa Cruz ${ }^{1,2, *}$ and Tomás López-Guzmán 1,3 \\ 1 Agrifood Campus of International Excellence, ceia3, University of Córdoba, 14071-Córdoba, Spain; \\ tomas.lopez@uco.es \\ 2 Faculty of Law and Business Administration, University of Córdoba, C/ Puerta Nueva, s/n. 14071-Córdoba, \\ Spain \\ 3 Faculty of Labour Sciences, University of Córdoba, C/ Adarve, 30 14071-Córdoba, Spain \\ * Corresponding Author: francisco.gonzalez@uco.es; Tel.: +34-957-218-837
}

\begin{abstract}
The recognition of a place as a World Heritage Site (WHS) by UNESCO is fundamental to preserve its historical and artistic inheritance and, at the same time, to encourage visits to that area. The purpose of this article is to contribute to the study of the relationship between WHS and cultural tourism, with a marked sustainable character, through the presentation of the results of research conducted in the city of Cordoba (Spain) and which analyses the sociodemographic profile of the tourists, the variables that influence their level of satisfaction and of their loyalty and the classification of the travelers through different variables. The principal results of the research show the significant educational level of the surveyed tourists, as well as the high level of satisfaction with the visit, the high number of countries of origin and the outstanding motivation for knowing the city's heritage roots.
\end{abstract}

Keywords: cultural tourism; world heritage site; sustainability; satisfaction; cordoba; Spain

\section{Introduction}

Annually the WHS Centre of the UNESCO in Paris publishes three lists: World Heritage Site (WHS), Intangible Cultural Heritage and World Heritage in Danger. Furthermore, in the first and third lists, it indicates whether this element is a cultural, natural or mixed element. The inclusion of a certain place or intangible element in the list supposes the consideration of an exceptional universal value and, at the same time, that inscription allows understanding that all the persons of the world are owners of (and are responsible for) that place or intangible element. With this it seeks, moreover, its sustainability. In this way, and according to Saipradist and Staiff [1], the World Heritage lists reinforce the identification, preservation and transmission towards future generations of extraordinary places and monuments from the perspective of history and of art.

Nonetheless, although the main purpose of these recognitions by the UNESCO is to preserve and conserve these sites, it has signified in many cases, a significant increase of tourists, especially from other countries, in these places, generating a strong relationship between these lists and tourism [2]. In this way, it is paradoxical that, while the basic objective of the UNESCO in the designation of the WHS is to promote their protection and preservation, some destinations are prioritising their tourist development [3], especially in the new designations, little known by the tourists, where it begins by encouraging domestic tourism and, subsequently, a strong commitment to international tourism is made [3] with the aim of economically developing these geographical areas. That is to say, with the recognition by the UNESCO as WHS, the area is protected for future generations, but implicitly, at the same time, this mention implies an increase in tourism given the important attraction value [4-2], which in some cases can put into danger the very survival of the WHS. In fact, the inscription in the lists of World Heritage is the reason for which millions of tourists visit these places [5]. 
In this regard, culture becomes one of the most significant motivators of tourists in choosing a certain destination [6], which Di Giovine [7] defines as Heritage-Scape. There is an increase in the interest of the impact of tourism on World Heritage Sites in recent years [4]. Thus, it is necessary to reinforce the scientific studies that analyse the characteristics of the heritage tourists [8]. This type of information is basically to know this type of tourist and his behaviour with the aim of managing these destinations in a sustainable way [8] since the tourism could affect, and on occasions does affect significantly, the local culture [9].

The objective of this paper is to advance in the knowledge of the tourist who visits a WHS. For this, we analysed the results of a study that presents different aspects of this type of tourism visiting the city of Cordoba (Spain). Thus, we intend to know the sociodemographic profile, the level of satisfaction in relation to the different variables that are defined in the destination and that influence the loyalty and the classification thereof, using different variables such as age, accommodation and number of nights he remains in the city. To fulfil this objective, this paper is structured, after the introduction, in a second section where a review is made of the literature, a third section that presents a description of the city of Cordoba; a fourth where the methodology used is shown; and a fifth section providing the results of the research and its discussion. This paper ends with the conclusions of the study and the references used.

\section{Review of the literature}

The relationship between tourism and heritage is one of the most discussed subjects in recent years by the academic literature. Thus, an important part of the recent articles accept the idea that heritage tourism is not just anyone who visits the heritage/cultural attractions, with it being necessary to identify different types of heritage tourists [8]. In this regard, Poria et al., [10] present a triple focus with respect to this type of tourists: first, all the tourists that visit places with heritage attributes are heritage tourists; second, heritage tourists are those who are aware of the heritage attributes of the site; third, heritage tourists are those tourists that are motivated by the heritage attributes of the site and think that the site forms part of their own heritage. In addition, for Yan and Morrison [5], it is also essential to consider what importance the tourist gives to this site, that is, if he considers the importance of that heritage.

Furthermore, there are different studies in which the relationship between the WHS and tourism is analysed. Among others we can highlight those focussed on certain sites of Portugal [11-6], Canada [12], Israel [13], China [14], Romania [15], Spain [16] or Vietnam [8]. On the other hand, different books analyse this relationship, and among them we can underscore those of Timothy and Boyd [17], Di Giovine [7], Timothy [18] and Park [19]. In any case, we must specify that heritage tourism refers to the activities of visiting or of experiencing heritage areas whether they are natural, cultural or urban [8] and that involve the visitor seeking a connection with his roots and with his heritage [11].

This signifies that, on occasion, the designation of a certain site as WHS is perceived as "branding" [18] or "labelling" [20] and that the recognition by the UNESCO, in addition to reinforcing the protection of the heritage, has a strong attraction for the tourist, signifying a global recommendation so that a certain type of tourists visit that destination [21], especially for those that travel seeking authentic experiences and genuine places [22]. For this reason, heritage is seen as one of the most significant and fastest growing aspects of tourism [13]. According to Vong and Ung [23], there are four factors related to heritage tourism: history and culture, facilities and services at heritage sites, heritage interpretation and heritage attractions.

Currently two research lines exist in this field [3]: first, the classification and the definition of heritage and of heritage tourism; second, the relationship between conservation and preservation of the heritage and the tourism development that is carried out in these areas. On the other hand, and according to Timothy and Boyd [17], the analysis of heritage tourism can be done through two different channels: first, the simple presence of the visitors in sites where the heritage is found, that is, the visit to certain destinations where the tourists find that the heritage is not part of their own history or culture and they are positioned as a mere visitor [1], which implies that it is necessary to 
consider the transcultural context of the heritage sites [1]; second, the perceptions that the visitors feel in these places, which means, according to the contributions of Poria et al. [10], that a visitor in a certain heritage site not only seeks a recreational experience but rather, on occasion and for certain tourists, he seeks part of his own roots in the visit to these historical sites. In short, and in both channels, it is necessary to reinforce the understanding of the WHS and clarify the cross-cultural attitudes towards the designation [10], especially when it deals with international tourists [24].

Moreover, the tourists decide to travel because they have internal and external motivations [6] and in some specific types of tourism the culture becomes one of the principal attractions. In turn, one must analyses both the destination, since a great diversity of sites exist, and the different variables that affect each of them [2]. At the same time, there is strong competition between the destinations to attract tourists, especially international ones [11]. In fact, heritage is one of the attributes that differentiates some sites from others, due to the complex system in which the destination is included and to the sustainable development with many facets in which the cultural inheritance has to be preserved [25-15]. In this regard, it is necessary to reinforce in the tourism destination such aspects as the quality of the accommodations, cleanliness, citizen safety and gastronomy, adapting them to the needs of this type of tourists. According to Abuamoud et al. [9] the demand of tourists in the heritage sites is also influenced by the services provided by the public authorities and by the availability and feasibility of the local community to stimulate tourism in these areas. In this regard, it becomes necessary to identify and understand the types of heritage tourists, their motivations, behaviour, perceptions and experiences in order to carry out better management of the destinations and to define the corresponding adapted strategies, seeking as a priority the sustainability and safeguarding of the heritage that makes them unique. In short, better knowledge of the tourist that visits these places implies an improvement in the management of the destination, seeking, above all, the sustainability of the historical heritage that attracts this type of tourist.

The variety of places and visitors creates significant differences for knowing the visitors' characteristics and, therefore, as indicated earlier, the better management of these places. And all this must also take into account that the behaviour model of the tourists visiting these places is different in each case [10].

In the studies conducted to define the sociodemographic profile of the tourists, the different authors coincide in that they have high education, the majority with university studies $[1,6,11]$. Likewise, this type of tourists expresses significant satisfaction with respect to the visited sites [2], satisfaction related basically with three groups of variables existing at the destination: novelty, knowledge and facilities [6], variables that allow orienting and reinforcing the different tourism management policies.

\section{Description of the geographic area}

The city of Cordoba is situated in the south of Spain, specifically in the region of Andalusia, a geographic area where there is strong sun-and-beach tourism as well as an important focus on cultural tourism with World Heritage cities such as Granada and Seville, in addition to Cordoba. The population of the city is approximately 325,000 inhabitants and its economic structure is based fundamentally on the tertiary sector, with the tourist activity and the public administration being predominant. The city has two declarations of World Heritage Sites by the UNESCO, the first in 1984 was the Mosque-Cathedral and, subsequently, in 1994 this classification was granted to its Historic Centre. Furthermore, the Festival of the Patios, which is held in the month of May, was declared Intangible Cultural Heritage in 2012. In addition, Cordoba, as the rest of Andalusia, also has the so-called Mediterranean Diet and Flamenco declared Intangible Cultural Heritage. All these recognitions imply that, at present, the city is one of the most representative of cultural tourism, both in Spain and in the rest of Europe, and constitutes a meeting point for thousands of travelers that each year arrive in the city, attracted by its rich cultural, heritage and historic inheritance. In Table 1, the evolution of the number of travelers and of overnight stays is shown for the 2011-2015 period, in 
accordance with the data of the Hotel Occupancy Survey conducted by the Spanish National Statistics Institute (NSI) [26].

Table 1. Evolution of the number of tourists and overnight stays in the city of Cordoba. Period 2011-2015.

\begin{tabular}{|c|c|c|c|c|c|}
\hline Year & $\mathbf{2 0 1 1}$ & $\mathbf{2 0 1 2}$ & $\mathbf{2 0 1 3}$ & $\mathbf{2 0 1 4}$ & $\mathbf{2 0 1 5}$ \\
\hline National tourists & 446,735 & 449,032 & 459,733 & 478,166 & 496,923 \\
Foreign tourists & 344,899 & 364,825 & 364,365 & 421,703 & 457,011 \\
Total Tourists & 791,634 & 813,857 & 824,098 & 899,869 & 953,935 \\
& & & & \\
National overnight stays & 737,991 & 746,064 & 756,340 & 777,470 & 839,404 \\
Foreign overnight stays & 511,882 & 539,985 & 534,663 & 615,374 & 697,863 \\
\hline Total overnight stays & $1,249,873$ & $1,286,049$ & $1,291,003$ & $1,392,844$ & $1,537,267$ \\
\hline \multicolumn{5}{c}{ Source: Own elaboration based on NSI [26]. } \\
\end{tabular}

As can be observed in Table 1, the increase in the number of tourists in the analysed time period was $20 \%$, with the case of tourism from other countries being more than $32 \%$, data that endorse the importance of this cultural destination. A significant increase has also been produced in the number of overnight stays (23\%), with the case of the international tourists being $36 \%$.

\section{Materials and Methods}

\subsection{Survey instrument}

The survey used in this research is based on different previous papers $[13,2,23]$ responds to two groups of variables analysed with respect to the tourists that visit the city: first, the sociodemographic profile of the surveyed tourist and the principal characteristics of the trip organisation; and second, the determination of those factors that define the satisfaction of the visit and its repetition. In the survey, questions were used with yes/no type responses as well as open responses. In addition, in others, the five-point Likert Scale $(1=$ not important; $5=$ very important $)$ was used.

As for the questions that appear in the survey referring to the sociodemographic profile of the visitor, gender, age, educational level, professional category, country of origin and income level were analysed. In order to analyse the satisfaction of the tourist with this destination, a series of variables were considered, such as hospitality, visitors' information points, historic heritage, citizen safety, cleanliness of the city, and the restaurants. Furthermore, these variables are used to determine the loyalty to this tourism destination. Finally, and to characterise the visitor, variables were analysed related to the type of accommodations in the city of Cordoba, the number of overnight stays of the tourist, the way in which the accommodation reservation had been made and the analysis of how the trip was made.

\subsection{Data compilation}

The researchers, using the questionnaire indicated above, compiled the information on the opinion of the tourists during the months of April to June 2014. The surveys were conducted at five survey points, located within the historic centre, and with the premise that the surveyed tourist had already spent some time in the city and, therefore, could give an informed opinion [13,11].

A total of 873 surveys were conducted, of which 816 surveys were useable. The participants filled out the survey with complete independence, although the surveyors were present in case they had any type of difficulty in filling it out. It was distributed in four languages (Spanish, English, French and German), and was completely anonymous. Previously a pre-test of 30 surveys was conducted to detect possible deviation and errors. Convenience sampling was used, common in this type of research, where the surveyed persons are available to be surveyed in a determined space and 
time [27]. Stratification by countries was carried out, according to the percentages of the tourists coming from each of them, according to the NSI data [26]. In this regard, among the countries sending international tourists France (25.1\%), United Kingdom (11.1\%) and Germany (7.1\%) stand out. Therefore, taking into account that the number of tourists staying in hotels of the city of Cordoba in 2013 (latest datum available at the time of conducting this research) [26] was 824,098, the sampling error of the research was $+/-3.42 \%$.

\subsection{Data analysis}

With respect to the data analysis, in the first place the sociodemographic profile of the tourist that visits the city of Cordoba is presented, in accordance with the variables explained above. Next, a factorial analysis was conducted, with Varimax rotation, on the aspects related to the visit; analysis of internal consistency of the factors (Cronbach's Alpha), and logistic regression analysis, for the purpose of discovering the probability of a tourist repeating the trip to the city of Cordoba, introducing in the models as independent variables the factors obtained in the factorial analysis to determine which of them makes the cited probability increase/decrease significantly.

Finally, a multiple correspondence analysis is presented that allows studying graphically the relationship existing between the variables to analyse using a multivariate approach. With this, it makes it possible to summarise the information by means of some factors that are obtained from the linear combination of original variables and that constitute the axes of coordinates of the graph in which the information is represented.

The statistical analysis was conducted with the SPSS 22.0 program for Windows. The differences considered statistically significant are those whose $\mathrm{p}<0.05$.

\section{Results}

The first objective of this research was to know the sociodemographic profile of the tourist visiting the city of Cordoba. Table 2 presents the cited profile in accordance with the following variables: gender, age, income, educational level, country of origin and professional category. It should be recalled that in relation to the country of origin of the surveyed person, the strata established by the NSI [26] was followed in the field work. 
Table 2. Sociodemographic profile of the tourists.

\begin{tabular}{|c|c|c|c|c|c|}
\hline Variables & & Percentage & Variables & & Percentage \\
\hline $\begin{array}{l}\text { Gender } \\
(\mathrm{N}=816)\end{array}$ & $\begin{array}{c}\text { Man } \\
\text { Woman }\end{array}$ & $\begin{array}{l}46.7 \% \\
53.3 \%\end{array}$ & $\begin{array}{l}\text { Educationa } \\
\qquad 1 \text { level } \\
(\mathrm{N}=803)\end{array}$ & $\begin{array}{c}\text { Primary } \\
\text { education } \\
\text { Secondary } \\
\text { education } \\
\text { University } \\
\text { education }\end{array}$ & $\begin{array}{l}4.8 \% \\
23.6 \% \\
71.6 \%\end{array}$ \\
\hline $\begin{array}{c}\text { Age } \\
(\mathrm{N}=815)\end{array}$ & $\begin{array}{l}\text { Under } 30 \text { years } \\
\quad \text { of age } \\
30-39 \text { years old } \\
40-49 \text { years old } \\
50-59 \text { years old } \\
60 \text { years old or } \\
\text { more }\end{array}$ & $\begin{array}{l}16.7 \% \\
19.0 \% \\
17.2 \% \\
22.1 \% \\
25.0 \%\end{array}$ & $\begin{array}{c}\text { Country of } \\
\text { origin } \\
(\mathrm{N}=816)\end{array}$ & $\begin{array}{c}\text { Spain } \\
\text { France } \\
\text { Germany } \\
\text { United Kingdom } \\
\text { USA } \\
\text { The Netherlands } \\
\text { Japan } \\
\text { Belgium } \\
\text { Portugal } \\
\text { Other }\end{array}$ & $\begin{array}{c}52.5 \% \\
9.7 \% \\
6.1 \% \\
5.5 \% \\
4.4 \% \\
2.6 \% \\
1.8 \% \\
1.4 \% \\
1.1 \% \\
14.9 \%\end{array}$ \\
\hline $\begin{array}{c}\text { Income } \\
(\mathrm{N}=703)\end{array}$ & $\begin{array}{c}\text { Under } € 700 \\
\text { From } € 700 \text { to } € \\
1,000 \\
\text { From } € 1,001 \text { to } € \\
1,500 \\
\text { From } € 1,501 \text { to } € \\
2,500 \\
\text { Over } € 2,500\end{array}$ & $\begin{array}{l}48.1 \% \\
21.9 \% \\
21.1 \% \\
\\
5.5 \% \\
3.4 \%\end{array}$ & $\begin{array}{c}\text { Occupation } \\
\text { al } \\
\text { Category } \\
(\mathrm{N}=796)\end{array}$ & $\begin{array}{c}\text { Employee } \\
\text { Retired } \\
\text { Civil Servant } \\
\text { Self-employed } \\
\text { Student } \\
\text { Housewife } \\
\text { Other }\end{array}$ & $\begin{array}{c}32.6 \% \\
17.0 \% \\
16.9 \% \\
15.9 \% \\
9.4 \% \\
7.6 \% \\
0.6 \%\end{array}$ \\
\hline
\end{tabular}

Source: Own elaboration.

According to Table 2, the profile of the tourist visiting the city of Cordoba is a person with university studies, with a quite similar age distribution, although the persons over 40 years of age prevail, with a medium-high income level and with a predominant professional category of employee. As for the nationality of the visitors, in this research profiles were gathered from surveyed persons from 39 different countries. This important number of countries allows concluding that, with an appropriate promotion and given the broad cultural and geographic spectrum of the foreign visitors, an increase in the number of tourists that visit the city of Cordoba could be managed, since its tourism is not limited to a specific and reduced number of countries.

A factorial analysis is presented below to determine what items are related to the satisfaction of the visit to the city of Cordoba. As observed in Table 3, three factors with eigenvalue over 1 were obtained, taking as criteria for assigning an item to the factor those in which factorial loading over 0.50 is presented, which explained $64.8 \%$ of the total variance. The first factor, responsible for $25.1 \%$ of the total explained variance, included the items that reflect the aspects related to the visit and that we call tourist values. In the second factor $(21.8 \%$ of the variance) are grouped the items that estimate the dimension called stay. The third and last factor was called complementary services and explains the $17.9 \%$ of the variance. The three factors present Cronbach's Alpha over 0.80 and, therefore, we can assume that the items that form them measure the same construct and are highly correlated. 
Table 3. Factorial analysis of satisfaction items of visit to Cordoba $(n=816)$.

\begin{tabular}{|c|c|c|c|}
\hline & \multicolumn{3}{|c|}{ Factor } \\
\hline & $\begin{array}{l}\text { Tourist } \\
\text { values }\end{array}$ & Stay & $\begin{array}{c}\text { Complementary } \\
\text { services }\end{array}$ \\
\hline Fiesta of the Patios & .679 & & \\
\hline Hospitality/treatment & .639 & & \\
\hline Preservation of the area & .779 & & \\
\hline Cultural activities and shows & .697 & & \\
\hline Mosque-Cathedral & .872 & & \\
\hline Historic District (Jewish Quarter) & .833 & & \\
\hline Signage & & .821 & \\
\hline Accommodation & & .780 & \\
\hline Citizen Safety & & .682 & \\
\hline Cleanliness & & .762 & \\
\hline Ease of public parking & & .848 & \\
\hline Restaurants & & & .679 \\
\hline Bars and taverns & & & .614 \\
\hline Commercial areas & & & .538 \\
\hline Taxis & & & .548 \\
\hline Internet connection & & & .567 \\
\hline Information and visitor assistance points & & & .547 \\
\hline Eigenvalues & 2.79 & 2.10 & 1.80 \\
\hline$\%$ Explained variance & 25.01 & 21.83 & 17.97 \\
\hline$\%$ Accumulated explained variance & 25.01 & 46.84 & 64.81 \\
\hline KMO & & & \\
\hline Bartlett sphericity test & & & \\
\hline
\end{tabular}

NOTE: Extraction method: Analysis of principal components. Rotation method:

Varimax standardisation with Kaiser. The rotation has converged in 5 iterations.

Source: Own elaboration.

Next, a logistic regression is presented to determine the probability that a tourist may repeat the trip to the city of Cordoba. Thus, the three groups obtained previously through the factorial analysis (tourist values, stay and complementary services) were introduced in the logistic regression model as independent variables, to determine which of them makes the probability significantly increase or decrease of a tourist repeating the trip to the city. In Table 4 the results of the logistic regression analysis are shown. 
Table 4. Logistic Regression Analysis ( $n=779)$.

\begin{tabular}{|c|c|c|c|c|c|c|}
\hline Variables & B & SE & Wald & Odds ratio & $95 \% \mathrm{CIt}$ & $\mathbf{p}$ \\
\hline Tourist values & 1.32 & .24 & 31.14 & 3.74 & $2.35-5.95$ & $<.001$ \\
\hline Stay & .03 & .22 & .02 & 1.03) & $.67-1.59$ & .897 \\
\hline Complementary services & .95 & .10 & 85.00 & 2.59 & $2.11-3.16$ & $<.001$ \\
\hline Constant & 1.39 & .55 & 6.47 & & 4.0 & .011 \\
\hline $\begin{array}{l}\text { Model: } \\
x^{2}=75.78 ; \mathrm{p} \times, 001 \\
\text { Hosmer and Lemeshow: } \\
\chi_{\mathrm{g}}^{2}=9.59 ; \mathrm{p}=295 \\
\text { Nagelkerke } \mathrm{R} 2=.432\end{array}$ & & & & & & \\
\hline
\end{tabular}

${ }^{\dagger}$ Confidence interval for odds ratio Source: Own elaboration

We observe that the tourist values $(\mathrm{OR}=3.74)$ and the complementary services $(\mathrm{OR}=2.59)$ increase the probability that a tourist will again visit the city. We consider that this result may be due to the actual importance that is given to the cultural heritage of the city and to the complementary services that complete its offer, as a fundamental part that defines the tourist experience and, therefore, as key elements for loyalty and the dedication to the destination in the aspect of a return visit. Furthermore, the stay factor did not present a significant effect $(p=0.897)$. This is curious since the aspects related to these items, especially citizen safety, is usually valued highly when deciding whether or not to again visit a certain tourism destination, but it could be due to the prior conceptualisation of Spain as a country with a high level of quality and safety in the stay. Finally, it should be indicated that the model classified correctly $89.7 \%$ of the tourists that affirmed they would again visit the city, and in total it classified $93.1 \%$ correctly.

To end this section, below is presented a multiple correspondence analysis, for the purpose of studying the relationships between the variables of age, accommodation, overnight stays, reservations and travel method, with the objective of characterising the type of traveler. The information related to the studied tourists is grouped around two axes: a first axis is defined by age, distinguishing the tourists with an age equal to or under 40 years and those over 40 years of age, and a second axis that is determined by the type of accommodation. These axes explain $76.6 \%$ of the variability associated with the qualitative variables studied.

Therefore, in the first quadrant are grouped the tourists under 30 years of age that travel with friends and that do not stay overnight in the city. The second group of travelers (quadrant II) are characterised by having an age starting at 40 years who travel as a couple, stay in hotels, manage their trip through tourist intermediaries and spend two nights in the city. The last group of travelers (quadrant IV) is formed by tourists with an age between 30 and 39, who travel as a couple with children, choose hostels or apartment for their accommodation which is managed personally and that spend at least three nights in the city. These results are presented in Figure 1. 
Figure 4. Relationship between the variables of the study (multiple correspondence analysis).

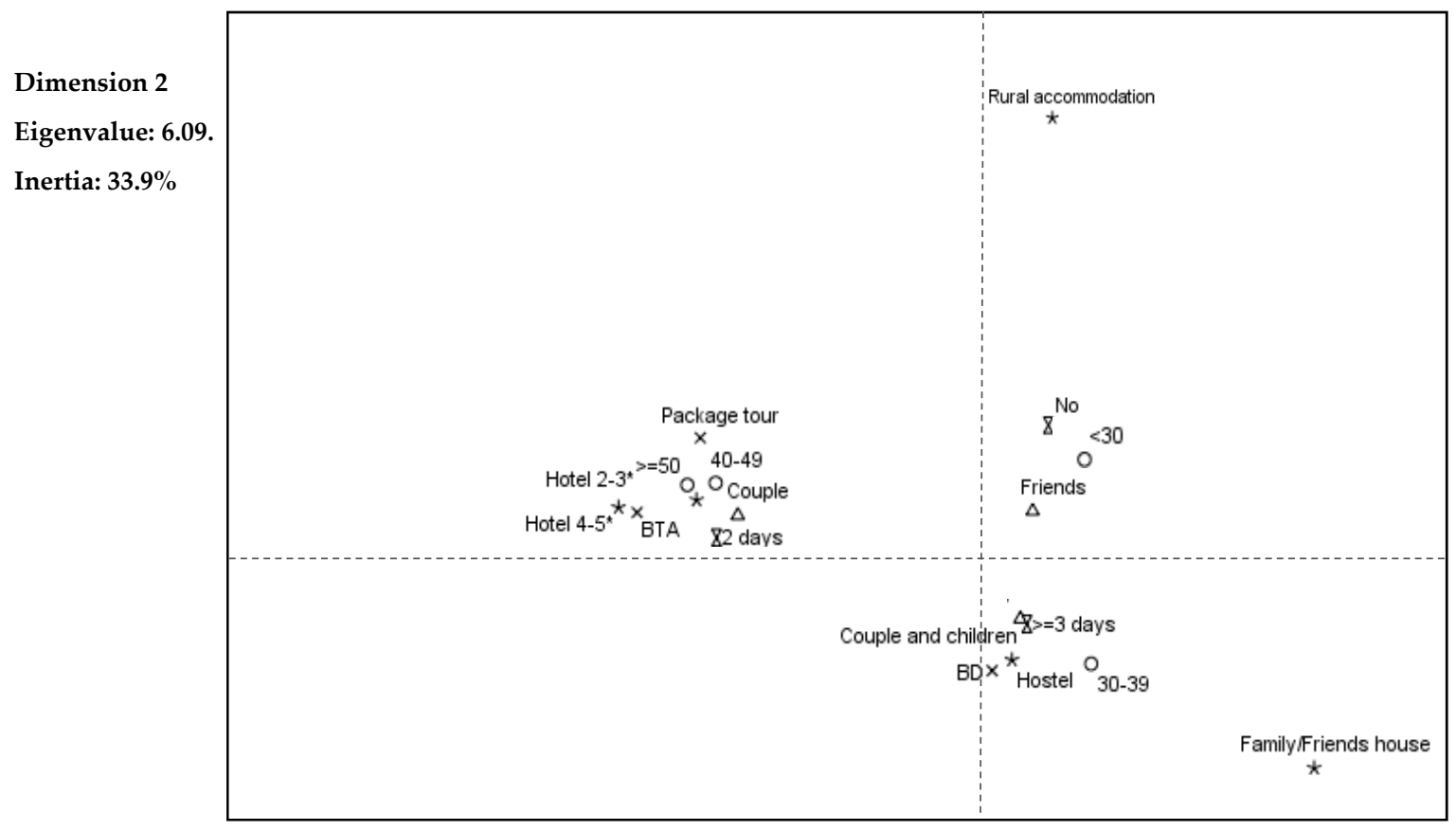

Dimension 1

Eigenvalue: 7.69 . Inertia: $42.7 \%$

Source: Own elaboration

\section{Discussion and conclusions}

Granting a certain city or area the classification of World Heritage Site by the UNESCO means, in addition to a cultural recognition and the obligation of its preservation by the different public administrations and private companies, an important attraction for promoting a destination in relation to a certain type of tourists and, therefore, it also implies the need to correctly manage this area, prioritising in this development, above all, its sustainability and maintenance for future generations. In this paper, research is presented that undertakes the study of the tourism demand in the city of Cordoba, a World Heritage city.

Therefore, the results are presented of a study that encompasses the sociodemographic profile of the tourist that visits the city, the variables that influence his satisfaction and the classification of said tourist. Among the principal conclusions it is interesting to highlight the predominant sociodemographic profile of the tourist, specifically a person with university-level education, with a medium-high income and who works for others, who has known the city of Cordoba through recommendations of friends and family, and that has a high degree of loyalty to the destination. On the other hand, three grouped factors have been detected (tourist values, stay and complementary services) that explain the satisfaction with respect to the visit to Cordoba, with the first and the third standing out among them. Furthermore, the multiple correspondence analysis clearly groups the travelers by age, where the younger ones (less than 30 years of age) travel more informally and without overnight stays in the city, going on to the range of 30 to 40 years who travel with the family and preferring the hostels and apartments that they themselves organised and, finally, those over 40 years who, in addition to using tourism intermediaries, stay in hotels of the city.

We consider that the main practical application of this research is to contribute to understanding the sociodemographic characteristics of the tourists that visit the city and the variables that most influence their satisfaction, as well as their classification, with the aim of conceiving tourism and cultural products that satisfy better the needs of the tourists and that, at the same time, is compatible with the sustainable management of this tangible heritage. 
As with all research, this study also has a high number of limitations. Among them we highlight, basically, the date of conducting the surveys to the tourists, which was during the months of April to June 2014, that is, during the months when the city attracts the greatest number of visitors; therefore, the rest of the months of the year should be considered during which the inflow of tourists is not as high.

As future lines of research, we pose going into depth in the study of heritage tourism, carrying out similar studies in other cities declared by the UNESCO as World Heritage Sites, in order to be able to identify common links and differentiating features among the visitors.

Acknowledgments: The authors of this paper wish to thank the Cordoba Local Tourist Board of the City of Cordoba, Spain, for their support in conducting this research.

Author Contributions: All the authors conceived, designed and performed the experiments. They also analyzed the data and wrote the article.

Conflicts of Interest: The authors declare no conflict of interest.

\section{References}

1. Saipradist, A.; Staiff, R. Crossing the cultural divide: Western visitors and Interpretation at Ayutthaya World Heritage Site, Thailand. J. Herit. Tour. 2008, 2 (3), 211-224.

2. Breakey, N. M. Study in of World Heritage visitors: The case of the remote Riversleigh Fossil Site. Visit. Stud. 2012, 15 (1), 82-97.

3. Su, M. M.; Wall, G. Chinese research on World Heritage Tourism. Asia Pac. J. Tour. Res. 2011, 16 (1), 75-88.

4. Landorf, C. Managing for sustainable tourism: a review of six cultural World Heritage Sites. J. Sustain. Tour. 2009, 17 (1), 53-70.

5. Yan, C.; Morrison, A. The influence of visitors' awareness of World Heritage Listings: a case study of Huangshan, Xidi and Hongan in Southern Anhui, China. J. Herit. Tour. 2007, 2 (3), 184-195

6. Correia, A.; Kozak, M.; Ferradeira, J. From tourist motivations to tourist satisfaction. Int. J. Cult. Tour. Hosp. Res. 2013, 7 (4), 411-424.

7. Di Giovine, M. A. The heritage-scape. UNESCO, World Heritage, and tourism; Lexington Book: New York, USA, 2009.

8. Nguyen, T. H. H.; Cheung, C. The classification of heritage visitors: a case of Hue City, Vietnam. J. Herit. Tour. 2014, 9 (1), 35-50.

9. Abuamoud, I. N.; Libbin, J.; Green, J.; Alrousan, R. Factors affecting the willingness of tourists to visit cultural heritage sistes in Jordan. J. Herit. Tour. 2014, 9 (2), 148-165.

10. Poria, Y.; Reichel, A.; Biran, A. Heritage site management. Motivations and expectations. Ann. Touris. Res. 2006, 33, 162-178.

11. Remoaldo, P. C.: Vareiro, L.; Ribeiro, J. C.; Santos, J. F. Does gender affect visiting a World Heritage Site? Visit. Stud. 2014, 17 (1), 89-106.

12. Donohoe, H. M. Sustainable heritage tourism marketing and Canada's Rideau Canal world heritage site. J. Sustain. Tour. 2012, 20 (1), 121-142.

13. Poria, Y.; Butler, R.; Airey, D. The core of heritage tourism. Ann. Touris. Res. 2003, 30, 238-254.

14. Yang, C.H.; Lin, H. Y. Revisiting the relationship between World Heritage Sites and tourism. Tour. Econ. 2014, 20 (1), 73-86.

15. Bucurescu, I. Managing tourism and cultural heritage in historic towns: examples from Romania. J. Herit. Tour. 2015, 10 (3), 248-262.

16. Antón, C.; Camarero, C.; Laguna-García, M. Towards a new approach of destination royalty drivers: satisfaction, visit intensity and tourist motivation. Curr. Issues Tour. 2014, 1 (23), 238-260.

17. Timothy, D. J.; Boy, S. W. Heritage Tourism; Pearson Education: Harlow, UK, 2003.

18. Timothy, D. J. Cultural heritage and tourism: An introduction; Channel View Publications: Bristol, UK, 2011.

19. Park, H. Y. Heritage tourism; Routledge: London, UK, 2014.

20. Yang, C. H.; Lin, H. L.; Han, C.C. Analysis of international tourist arrivals in China: the role of World Heritage Sites. Tourism Manage. 2010, 31 (6), 827-837.

21. Poria, Y.; Reichel, A.; Cohen, R. Tourists perceptions of World Heritage Site and its designation. Tourism Manage. 2013, 35, 272-274. 
22. Timothy, D. J.; Boyd, S. W. Heritage tourism in the 21st Century: valued traditions and new perspectives. J. Herit. Tour. 2006, 1 (1), 1-16.

23. Vong, L. T.-N.; Ung, A. Exploring critical factors of Macau's Heritage tourism: what heritage tourists are looking for when visiting the city's iconic heritage site. Asia Pac. J. Tour. Res. 2012, 17 (3), 231-245.

24. Tucker, H.; Carnegie, D. World heritage and the contradictions of universal value. Ann. Touris. Res. 2014, 47, 63-76.

25. Bell, V. R. Experiencing heritage at a World Heritage Site: Personal encounters with Hadrian's Wall. Ann. Leis. Res. 2010, 13 (1-2), 167-190

26. Nacional Statistic Institute. Hotel Occupancy Survey; NSI Publications: Madrid, Spain, 2016.

27. Finn, M.; Elliott-White, M.; Walton, M. Tourism and leisure research methods: data collection, analysis and interpretation; Pearson Education: Harlow, UK, 2000.

(C) 2017 by the authors. Licensee Preprints, Basel, Switzerland. This article is an open access article distributed under the terms and conditions of the Creative Commons by Attribution (CC-BY) license (http://creativecommons.org/licenses/by/4.0/). 